\title{
Correction: Cancer from the perspective of stem cells and misappropriated tissue regeneration mechanisms
}

\author{
Mariusz Z. Ratajczak ${ }^{1,2} \cdot$ Kamila Bujko $^{1} \cdot$ Aaron Mack $^{1} \cdot$ Magda Kucia $^{1,2} \cdot$ Janina Ratajczak $^{1}$ \\ Published online: 7 March 2019 \\ (c) The Author(s) 2019
}

Correction to: Leukemia (2018) 32:2519-2526;

https://doi.org/10.1038/s41375-018-0294-7;

published online 30 October 2018
The original version of this Article omitted the following from the Acknowledgements:

OPUS grant UMO-2016/21/B/NZ4/00201 was awarded to MK.

Mariusz Z. Ratajczak

mzrata01@louisville.edu

1 Stem Cell Institute, Division of Hematology and Oncology, James Graham Brown Cancer Center, University Louisville, 500 South Floyd Street, Louisville 40202 Kentucky, USA

2 Department of Regenerative Medicine, Center for Preclinical Research and Technology, Warsaw Medical University, Warsaw, Poland

\section{Correction: Management of relapsed and refractory multiple myeloma: novel agents, antibodies, immunotherapies and beyond}

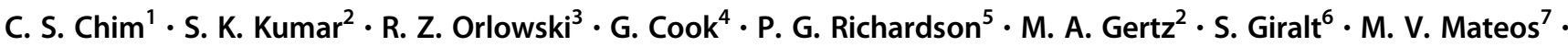 \\ X. Leleu $^{8} \cdot$ K. C. Anderson ${ }^{5}$ \\ Published online: 6 March 2019 \\ (c) The Author(s) 2019. This article is published with open access
}

C. S. Chim

jcschim@hku.hk

1 Department of Medicine, Queen Mary Hospital, The University of Hong Kong, Hong Kong, Hong Kong

2 Department of Medicine, Mayo Clinic at Rochester, Rochester, MN, USA

3 Department of Lymphoma/Myeloma, Division of Cancer Medicine, The University of Texas MD Anderson Cancer Center, Houston, TX, USA

4 Haematology \& Myeloma Studies, Section of Experimental
Haematology, Leeds Institute of Cancer and Pathology, University of Leeds, Leeds, UK

5 Department of Medical Oncology, Dana-Farber Cancer Institute, Harvard Medical School, Boston, MA, USA

Department of Medicine, Memorial Sloan Kettering Cancer Center, New York, USA

7 Department of Haematology, University Hospital of Salamanca, Salamanca, Spain

8 Hopital La Mileterie, part of the Academic Hospital of Poitiers (CHU), Poitiers, France 